\title{
Reducing temperature elevation of robotic bone drilling
}

\author{
Arne Feldmann ${ }^{\mathrm{a}, *}$, Jasmin $_{\text {Wandel }}^{\mathrm{b}}$, Philippe Zysset ${ }^{\mathrm{a}}$ \\ ${ }^{a}$ Institute for Surgical Technology and Biomechanics, University of Bern, Switzerland \\ ${ }^{b}$ Institute for Risks and Extremes, Bern University of Applied Sciences, Switzerland
}

\begin{abstract}
This research work aims at reducing temperature elevation of bone drilling. An extensive experimental study was conducted which focused on the investigation of three main measures to reduce the temperature elevation as used in industry: irrigation, interval drilling and drill bit designs. Different external irrigation rates $(0 \mathrm{ml} / \mathrm{min}, 15 \mathrm{ml} / \mathrm{min}, 30 \mathrm{ml} / \mathrm{min})$, continuously drilled interval lengths ( $2 \mathrm{~mm}, 1 \mathrm{~mm}, 0.5 \mathrm{~mm})$ as well as two drill bit designs were tested. A custom single flute drill bit was designed with a higher rake angle and smaller chisel edge to generate less heat compared to a standard surgical drill bit. A new experimental setup was developed to measure drilling forces and torques as well as the 2D temperature field at any depth using a high resolution thermal camera. The results show that external irrigation is a main factor to reduce temperature elevation due not primarily to its effect on cooling but rather due to the prevention of drill bit clogging. During drilling, the build up of bone material in the drill bit flutes result in excessive temperatures due to an increase in thrust forces and torques. Drilling in intervals allows the removal of bone chips and cleaning of flutes when the drill bit is extracted as well as cooling of the bone in-between intervals which limits the accumulation of heat. However, reducing the length of the drilled interval was found only to be beneficial for temperature reduction using the newly designed drill bit due to the improved cutting geometry. To evaluate possible tissue damage caused by the generated
\end{abstract}

*Corresponding author: Arne Feldmann, Tel.: +41 31631 5925, Fax: +41 316315959 , 凶arne.feldmann@istb.unibe.ch

Preprint submitted to Elsevier

July 7, 2016

(C) 2016. This manuscript version is made available under the Elsevier user license http://www.elsevier.com/open-access/userlicense/1.0/ 
heat increase, cumulative equivalent minutes (CEM43) were calculated and it was found that the combination of small interval length $(0.5 \mathrm{~mm})$, high irrigation rate $(30 \mathrm{ml} / \mathrm{min})$ and the newly designed drill bit was the only parameter combination which allowed drilling below the time-thermal threshold for tissue damage. In conclusion, an optimized drilling method has been found which might also enable drilling in more delicate procedures such as that performed during minimally invasive robotic cochlear implantation.

Wordcount: 5000 words

Keywords: bone drilling, temperature elevation of drilling, cooling, interval drilling, drill bit design, cumulative equivalent minutes, tissue damage, rake angle, chisel edge 


\section{Introduction}

3

4

6

Bone drilling is a surgical procedure which is used in many orthopaedic, dental, otolaryngological (head and neck) and other surgeries involving the human skeleton. Research on bone drilling has recently regained a lot of attention. One important aspect of the research concerns the production of heat during the drilling process. Comprehensive reviews of temperature elevation during bone drilling studies are presented by Augustin, Pandey and Bertollo et al. [1] [2] [3. Many previously reported studies, however, present statistically insignificant results and the varying experimental conditions and contradicting results make comparisons and conclusions difficult. Recently Tai et al. 44 evaluated numerically an optimized drilling strategy for multiple holes within a confined region. Various other attempts at modeling the drilling process have also been reported [5] 6] and considerable progress has been made, particularly in the calculation of drilling forces.

It has long been known that a temperature elevation of $47^{\circ} \mathrm{C}$ for 1 minute time exposure leads to bone necrosis [7], but the few clinical studies relating to this topic have not presented any evidence of clinically relevant outcomes (e.g. screw loosening) in orthopaedic surgery resulting from such exposure $[3$.

However, this is not true for otolaryngological surgeries which involve drilling or cutting procedures close to nerves. The recovery of damaged nerves takes a long time or is often not possible at all. The difficulties of otolaryngological surgeries is that the nerves (e.g. the facial nerve) lie within the bone and the total drilling depth can be higher than in orthopaedic surgeries which is around $9 \mathrm{~mm}$. A drilling depth of $25 \mathrm{~mm}$ is, for example, needed for the minimally invasive robotic cochlear implantation in which an access for inserting a cochlear electrode is drilled by a surgical robot 8. The drilling trajectory passes by the facial nerve as close as $0.5 \mathrm{~mm}$ which lies at a depth of $15-20 \mathrm{~mm}$ within the temporal bone. During a first-in-man in vivo trial it was found that the heat of the drilling process of a template based minimally invasive approach [9] resulted in facial nerve damage (palsy) in 1 out of 7 cases. This was confirmed in an 

temperature.
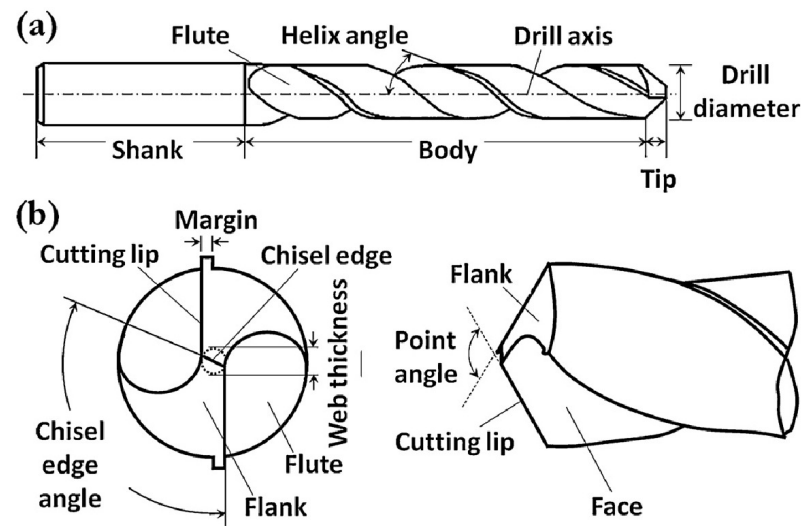

Figure 1: Annotation of standard drill bit: a) Whole drill bit b) Detailed view and description of the tip, Figure 2 can be additionally seen as a cross-section of the cutting lip and provides the description of rake and helix angle

Figure 1 shows the design of a standard drill bit. Many surgical drill bits are very similar to the standard design with the most important parameters being diameter, rake angle (in general equal to helix angle at outer diameter), 

general regardless of the drill bit design [16, 17.

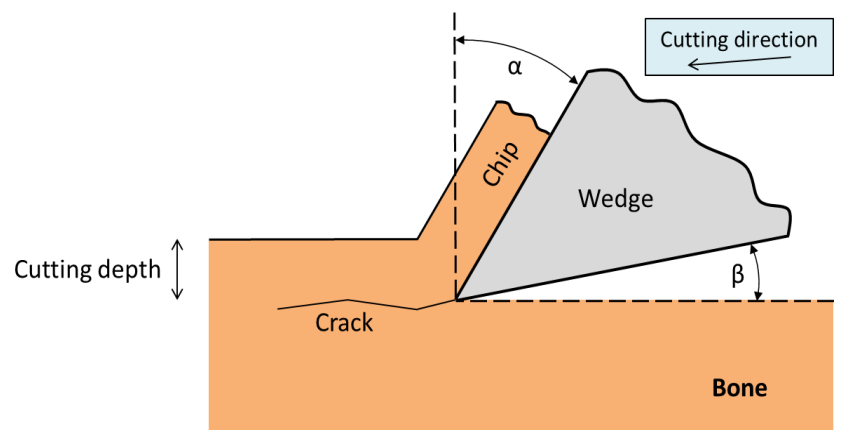

Figure 2: Orthogonal cutting process shows rake angle $(\alpha)$ and relief angle $(\beta)$ of an cutting edge and could also been seen as a simplified cross section through the cutting lip as seen in Figure 1. The rake angle of a drill bit is denoted at the outer diameter where it is equal to the helix angle. In general, bone fails rather in a fracture and not like metal in a shearing process if cutting depth is high [18.

relief angle, number of flutes and the design of the chisel edge. The chisel edge is the connection between the cutting edges of two fluted drill bits and is therefore minimized for 1- or 3-flute designs. The chisel edge has a negative rake angle which contributes up to $50 \%$ of the thrust force and is therefore often optimized with different design techniques (e.g. split-point, s-shaped) [12] [13]. Three fluted drill bits have the advantage of a superior bending stiffness, but no temperature reduction was found when comparing to 2-fluted drill bits [14] [15]. The drill bit diameter has been shown to increase the temperature elevation in

$$
\text { Researchers who investigated bone drill bit design [19] 12] [20] [21] 22] have }
$$
suggested lower temperature elevation with higher rake/ helix angle and smaller chisel edge and margins. Additionally it has been found that twist drills in general have a lower temperature elevation than K-wires [23] and that step-drill bit design does not significantly reduce the temperature elevation [24]. Other studies [25] 18] 26] 27] have focused on orthogonal cutting of bone to understand the basics of tool tissue interaction as shown in Figure 2. These studies found that the specific cutting energy decreases with higher rake angle or increasing cutting depth. Therefore, the authors hypothesize that a higher rake angle is beneficial for a lower temperature elevation. [13]. 
Another important method to reduce the temperature elevation is irrigation and several investigations into the effect of irrigation and the influence of flow rate and application method have been reported. Irrigation helps in dissipating the heat by convection and conduction, reduces the friction and can possibly help with the chip removal during the drilling process. There are two different types of irrigation, internal and external, which can be applied at different flow rates. Augustin et al. found external [17] irrigation as the most import single factor to reduce temperature elevation when internal irrigation cannot be applied [24]. Other authors 28, 29] suggested a combination of internal and external irrigation.

Just one study investigated the amount [30] $(\geq 500 \mathrm{ml} / \mathrm{min})$ while there is disagreement as to whether cold irrigation fluid or mist is beneficial [31] 23] or not [32]. To our knowledge, the positive influence of interval (incremental, intermittent, pecking) drilling on heat production has only been reported once [29]. This study investigates the drilling process in detail and focuses on the influence of irrigation, interval drilling and drill bit design on temperature elevation, thrust forces and torques. However, constant process parameters were used which are more applicable to automatized (robotic) surgeries. Additionally, an analysis of tissue damage is carried out in order to evaluate the safety of the proposed drilling strategies.

\section{Material and Methods}

\subsection{Experimental setup}

An experimental setup was designed to measure axial drilling forces, torques and temperature elevation. Figure 3 shows the setup which consists of a programmable CNC-machine (3-axis Miniflat i-TM 100-2, ISEL, Germany), a motor spindle (BFS-8015-12, Mechatron GmbH, Germany), a thermal (infrared) camera (A655sc, FLIR, USA) with a macroscopic lens (for $50 \mu m$ resolution) and a load cell (F310-400N-2Nm, Novatech, UK). For the irrigation, a surgical roller pump (IRRIG PP980, BienAir, Switzerland) with standard irrigation 
tube (Bien Air, Switzerland) was used allowing for the application of different flow rates (not shown in Figure 3).

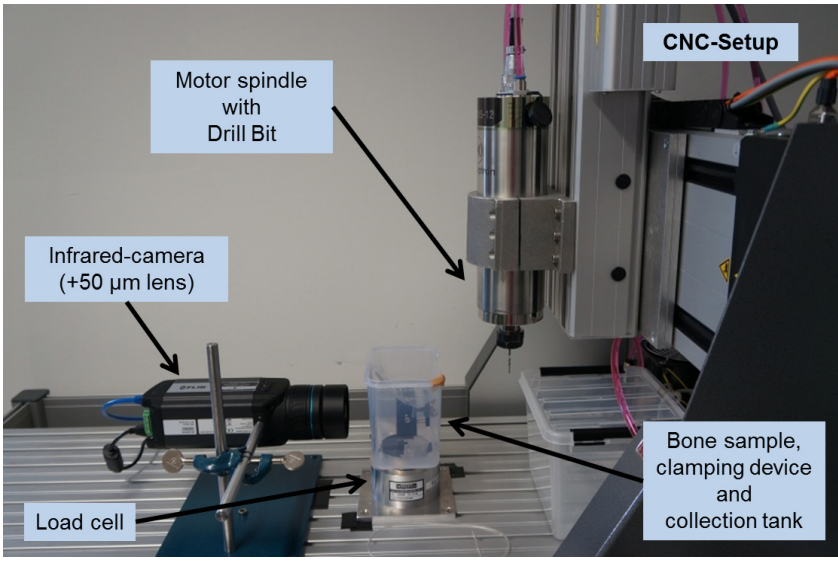

Figure 3: Experimental setup for measuring temperature elevations, thrust forces and torques of bone drilling at any drilling depth. External irrigation system not shown in this Figure.

The advantage of a thermal camera compared to thermocouples is the ability to measure a whole temperature field. Additionally, there are no concerns of proper contact or precise placement of thermocouples within the bone. The main disadvantage is that only the surface temperature field can be measured. To overcome this limitation, a special clamping device and bone sample preparation technique was used. Figure 4 shows the clamping device (made from POM), the bone sample dimensions and an example of the view of the thermal camera. A stiff $0.5 \mathrm{~mm}$ thick sealing mat was attached between the clamping device and the front surface of the bone, which was smoothly cut with a diamond saw. This prevented water leakage onto the field of view (thermographic area) and constrained the commencement of temperature measurements to a depth of 5 $\mathrm{mm}$. The thermographic area is $10 \mathrm{~mm} \times 30 \mathrm{~mm}$ ( $\mathrm{w} \times \mathrm{h}$ ) which complies with the maximal drilling depth of $25 \mathrm{~mm}$ for otolaryngological surgeries.

The emissivity constant of the bone's surface was determined in a separate experiment as $\varepsilon=0.96$ 33. For the irrigation, a standard 18 gauge needle (inner diameter: $\varnothing 0.838 \mathrm{~mm}$ ) was bent such that the water jet hits the tip of the drill bit with the angle $(\gamma)$ which is approximately equivalent to the helix 
angle of the drill bit. The irrigation fluid (water at $24^{\circ} \mathrm{C}$ room temperature) is collected in the collection tank and can flow into a second container(not visible in Figure 3).

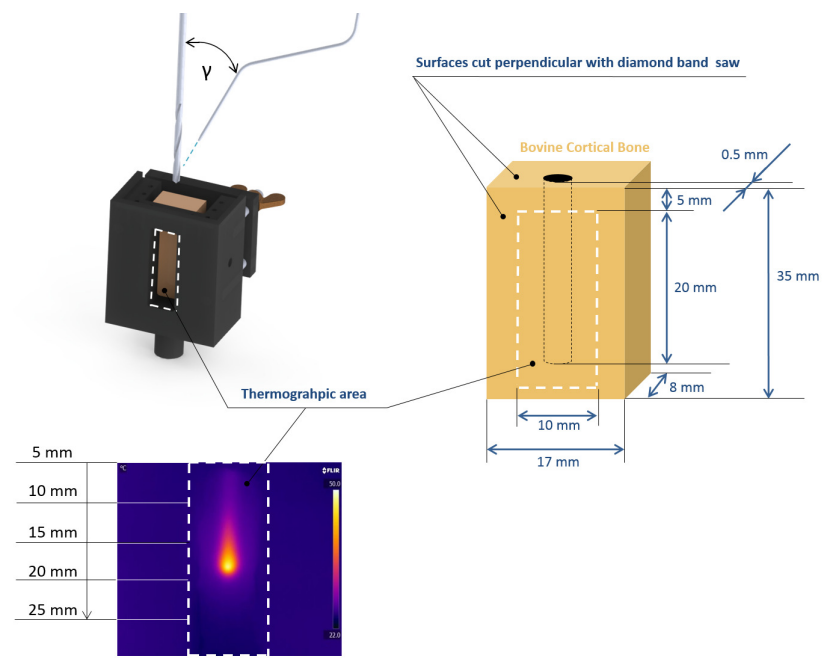

Figure 4: Clockwise: Detailed view of clamping device and irrigation, bone sample and drilling dimensions, thermal camera image with $50 \mu \mathrm{m}$ resolution. Thermal imaging starts at $5 \mathrm{~mm}$ depth for sealing purposes and prevention of water leakage onto the thermographic area.

\subsection{Sample preparation}

For these experiments, fresh frozen bovine tibiae of 4-year-old (milk) cows were used and acquired from a local slaughterhouse. They are largely available, optimal in size and it has been shown that bovine bone of this age can be used as a substitute for human bone due to the osteonal remodeling process 34. The frozen bone samples were pre-cut to the dimension in Figure 4 using a hand saw (the height corresponds to the axial direction of tibiae). Saline solution was used to irrigate the samples during the preparation process. In order to measure temperatures always at the same distance to the drilling trajectory and to allow proper sealing as well as to have a perpendicular top and side surface, a diamond band saw (Exakt Advanced Technologies GmbH, Germany) was used. The samples were refrozen and thawed for at least 3 hours in saline solution prior to the experiments. 


\subsection{Experimental procedure}

An experimental procedure was designed to capture the effects of external cooling and interval drilling as well as to compare a standard surgical drill bit with a drill bit which was newly designed by our group. Three different cooling rates $(0 \mathrm{ml} / \mathrm{min}, 15 \mathrm{ml} / \mathrm{min}, 30 \mathrm{ml} / \mathrm{min})$ and three different continuously drilled interval lengths $(0.5 \mathrm{~mm}, 1 \mathrm{~mm}, 2 \mathrm{~mm})$ were investigated.

The design of the study is condensed in Table1. Parameter combinations were selected to investigate either the influence of interval length with high irrigation or the influence of irrigation rate with an average interval length in order to show general relationships between both process parameters. Each factor combination considered (marked with a cross) was repeated 8 times for both drill bits, such that in total 80 experiments were carried out. Pilot holes had to be drilled for the standard drill bit due to its chisel edge and more flexible material which let to wandering issues.

Table 1: Design of experiments: Three different irrigation rates were tested in combination with three different continuously drilled interval lengths (with total drill bit extraction inbetween). Each parameter combination was conducted 8 times for both drill bits $(=80$ experiments).

\begin{tabular}{c|c|c|c} 
Interval \Irrigation & $0 \mathrm{ml} / \mathrm{min}$ & $15 \mathrm{ml} / \mathrm{min}$ & $30 \mathrm{ml} / \mathrm{min}$ \\
\hline $0.5 \mathrm{~mm}$ & & & $\mathrm{x}$ \\
\hline $1 \mathrm{~mm}$ & $\mathrm{x}$ & $\mathrm{x}$ & $\mathrm{x}$ \\
\hline $2 \mathrm{~mm}$ & & & $\mathrm{x}$
\end{tabular}

The input parameter interval denotes how many millimeters are continuously drilled (with a feed rate of $0.5 \mathrm{~mm} / \mathrm{s}$ ) before the drill bit (tip) is extracted up to 6 millimeters above the bone surface with a higher feed rate of $2.5 \mathrm{~mm} / \mathrm{s}$. Afterwards, the drill bit advanced again into the bone with the same feed rate and stopped $0.5 \mathrm{~mm}$ above the last drilled position to continue drilling the next interval with the slower standard feed rate $(0.5 \mathrm{~mm} / \mathrm{s})$. This procedure allowed the water jet to remove the chips and allows the irrigation liquid to enter the drilled hole when the drill bit is extracted. The rotational speed was set to 1000 RPM. Experiments were performed with both a standard two-flute and custom made single-flute drill bit (Figure 5), both with a diameter of $2.5 \mathrm{~mm}$. 


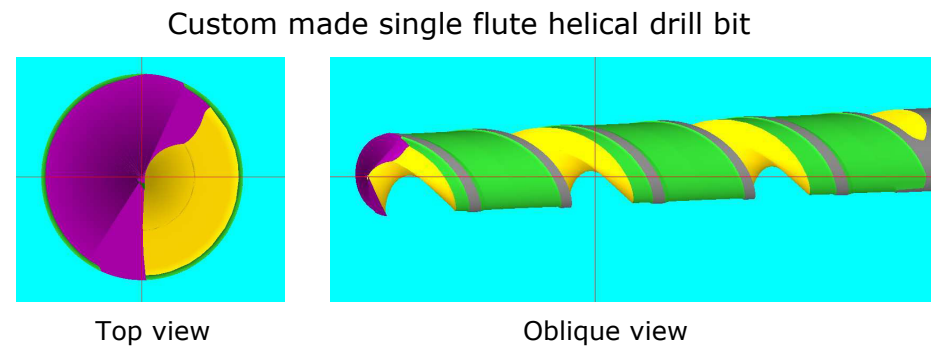

Figure 5: Custom made single flute drill bit. Top view on tip (left) shows the flank (purple) and oblique view (right) show that the drill bit has a single cutting edge and therefore also one helix (yellow) as well as a minimal chisel edge. The margin (grey) was designed to reduce friction by limiting the contact surface to the wall of the hole. The small asymmetry of drill bit is less important due to the use of stiff tungsten carbide material.

The custom-made tungsten carbide drill bit was designed and patented with a high rake angle $\left(\alpha=35^{\circ}\right)$ which results in a sharper wedge which in turn reduces cutting forces (torques) because it is assumed that it needs less forces to cut the material which is hypothesized to lead to a lower temperature elevation. Figure 2 can be seen as a cross-section of the cutting lip as denoted in Figure 1. In contrast to the standard drill bit, the custom-made drill bit has just one cutting edge which can be described as a gun drill with a spiral helix. This design allows manufacturing of high rake angles while minimizing the chisel edge and increasing the cutting depth per cutting edge. These measures could lower the specific cutting energy if the findings of orthogonal cutting tests are transferable to the drilling process. The standard two-fluted surgical drill bit (Synthes, Johnson\&Johnson, USA) has a lower rake angle and helix $\left(\alpha=16^{\circ}\right)$. Moreover it is made of surgical steel and thus, less rigid, but also less prone to breakage. Both drill bits had a $90^{\circ}$ point angle which improves centering on an oblique surface and a manufactured sharp without a defined radius on the cutting edge which reduces cutting forces but decreases the tool life [35].

For the temperature readouts, the maximal temperatures of the whole field were recorded for a frame rate of 12.5 frames per second and a resolution of $50 \mu \mathrm{m}$. The data was further processed using Matlab R2013a (Mathworks, USA) and the maximal temperature, force and torque for each drilled interval was extracted. 


\subsection{Statistical model}

A Bayesian linear regression model with random effects was used to compare the investigated combinations of drilling interval, irrigation and drill bit. This model accounts for the dependence amongst repeated experiments within each ID. Specifically, maximal temperatures were assumed to depend linearly on the drilling depth. Separate linear regressions were fitted for each ID. The random intercept and the random slope are normally distributed. In order to predict the expected outcome, prediction bands were calculated based on the predicted intercept and the predicted slope. Statistical analyses were performed using statistics software (R 3.2.0, JAGS 3.4.0 and Rstudio).

\section{Results}

\subsection{Temperature Elevation}

Figure 6 shows the local temperature maxima of each interval for each repetition for all parameter combinations. The $95 \%$ prediction bands for each parameter combination (ID) were simulated from the Bayesian random effects model and are represented by the red curves. Statistical analyses were not performed for $0 \mathrm{ml} / \mathrm{min}$ irrigation drillings (ID 3 and 8) because of saturation of the thermal camera $\left(160{ }^{\circ} \mathrm{C}\right)$ and thus violation of the model assumptions 


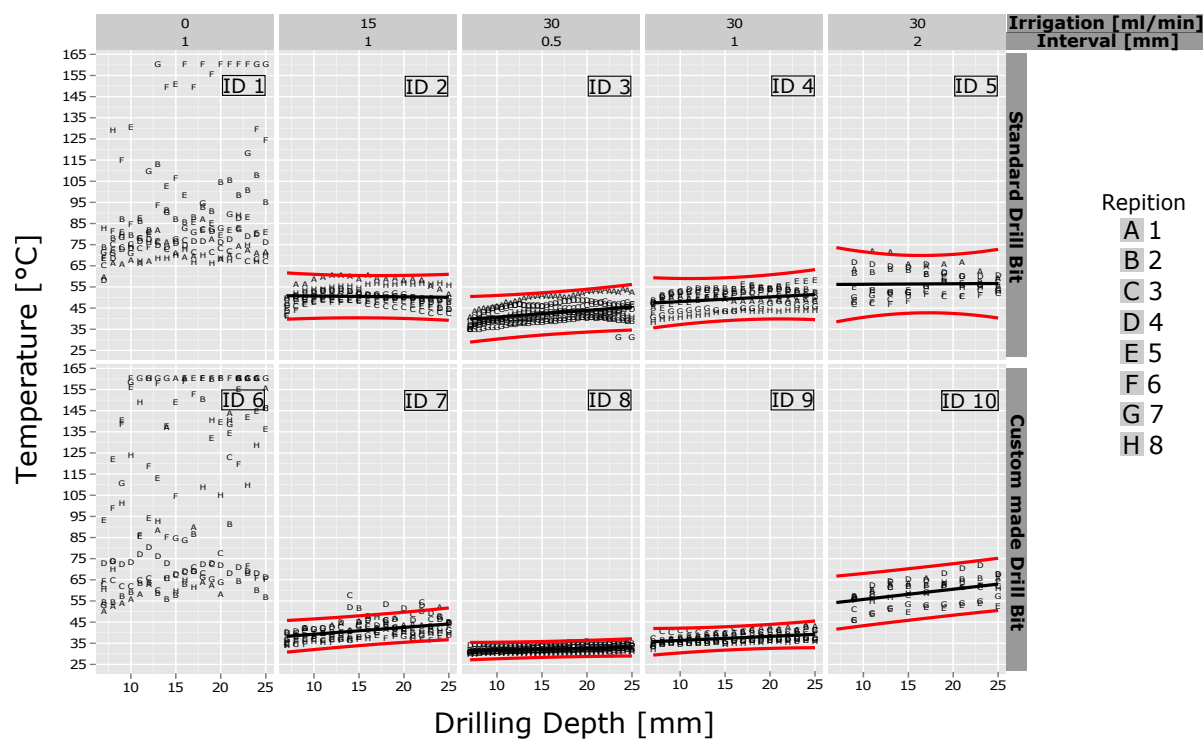

Figure 6: Letters denote the maximum temperature elevation within a drilled interval for all parameter combinations and repetitions over drilling depth. The top row shows the parameter combinations (ID) for standard drill bit while the results of the new custom made drill bit can be seen in the bottom row. Linear regression and $95 \%$ prediction bands are shown for most parameter combinations. The different letters $\mathrm{A}$ to $\mathrm{H}$ describe the repetitions of the experiments. Each parameter combination is labeled ID 1 to ID 10.

As can be seen in Figure 6, differences in temperature elevation during drilling were observed for the different drilling parameter combinations. The highest irrigation rate together with the smallest drilling interval and the new drill bit (ID 8) outperforms the others both in terms of maximal temperature and variation (narrow prediction bands). To further investigate the differences between the parameter configurations, the dependence on drilling depth was neglected. This choice was justified by the small increase in maximal temperature increase over the total drilling depth. 

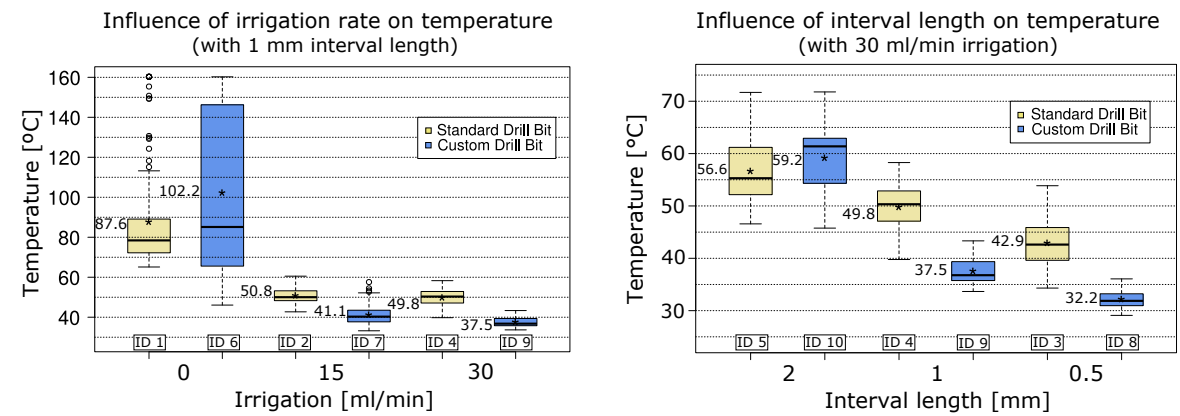

Figure 7: Maximum temperature elevation for each parameter combining temperature elevations of repetitions and drilling depths. Left: Relationship of irrigation rate and maximum temperature elevation for both drill bits. Right: Influence of the three continuously drilled interval lengths on maximum temperature elevation. Note that the maximum value of the $\mathrm{y}$-scale was changed.

Figure 7 shows the influence of irrigation (left) and interval length (right) on temperature elevation for the two different drill bits. A substantial decrease in the mean and the scattering of maximum temperatures can already be achieved by irrigating the drilling process with a low amount of irrigation fluid. A doubling of the irrigation rate to $30 \mathrm{ml} / \mathrm{min}$ has no substantial impact on the mean maximum temperature, but it further decreases the chance of encountering occasional higher temperature peaks. These high peaks result from chip getting stuck in the flutes [22]. They are more efficiently removed with a higher pressure jet $(30 \mathrm{ml} / \mathrm{min})$.

The influence of interval length for $30 \mathrm{ml} / \mathrm{min}$ irrigation on the maximum temperature is shown on the right side of Figure 7. Drilling in intervals is beneficial for the limitation of heat accumulation by allowing the bone and the drill bit to cool down in between intervals. By reducing the interval which is continuously drilled, the maximum temperature elevations are reduced. This is not surprising, because the time of energy (heat) transfer into the bone is shorter. On the other hand, more intervals are needed to reach a certain depth so that the total time of heat transfer increases. Comparing the behavior of the two drill bits, the new drill bit seems more sensitive to the decrease in interval length. 


\subsection{Tissue Damage}

All these reported temperatures are maximum peak temperatures for each drilled interval. However, the thermal damage of biological tissues is dependent on temperature elevation as well as time duration. To evaluate the tissue damage, the cumulative equivalent minutes at $43^{\circ} \mathrm{C}\left(\mathrm{CEM} 43^{\circ} \mathrm{C}\right)$ were used to relate time and temperature elevation [36. Each tissue or cell has a different threshold which rises exponentially with higher temperatures. The $\mathrm{CEM} 43^{\circ} \mathrm{C}$ value, mostly used for describing hypertermia in MR saftey or RF-heating treatment, can be calculated as [36]

$C E M 43^{\circ} C=\sum_{0}^{t_{\text {end }}} R(T(t))^{43-T(t)} \Delta t \quad$ with $\quad R(T(t))= \begin{cases}0.5, & \text { if } T(t)>43^{\circ} C \\ 0.25, & \text { otherwise }\end{cases}$

A more recent method by Tai et al. 4] could be used if only bone necrosis is investigated. Cumulative equivalent minutes were calculated for the three different interval lengths for both drill bits as shown in Figure 8 (with $\Delta t$ corresponding to the frames per second of the thermal camera). To investigate physiological tissue damage, the base room temperature of $24^{\circ} \mathrm{C}$ was shifted to body temperature of $36.7^{\circ} \mathrm{C}$. Introduced errors are neglected and temperatures are plotted for a single point at a depth of $15 \mathrm{~mm}$ (in Figure 8) which potentially represents the facial nerve position in minimally invasive robotic cochlear implantation surgeries. The six examples were chosen so that maximal temperature peaks correspond to the mean maximum temperature elevation (in Figure

7 (right) $\left.+12.7^{\circ} \mathrm{C}\right)$ of corresponding parameter combination $(0.5 \mathrm{~mm}, 1 \mathrm{~mm}, 2$ $\mathrm{mm})$. 

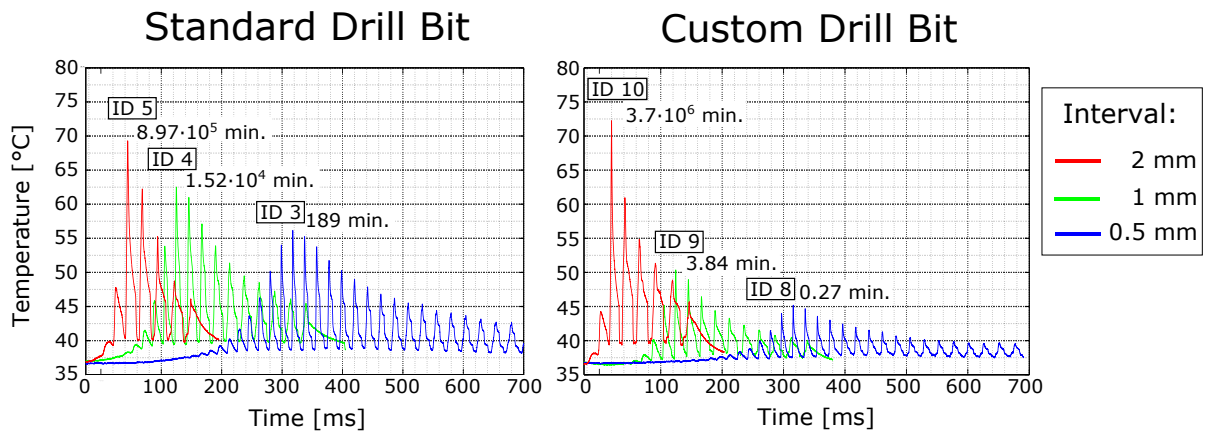

Figure 8: Examples of temperature curves for the three investigated interval lengths at a single point at $15 \mathrm{~mm}$ drilling depth. Temperatures were shifted from room $\left(24^{\circ} \mathrm{C}\right)$ to body temperature $\left(36.7^{\circ} \mathrm{C}\right)$. Maximal temperature peaks correspond to mean maximal temperature elevation of parameter combination in Figure 7 (right side). Left: Temperature elevation for the three intervals of a standard drill bit. Curves shifted over time for better visualization. Cumulative equivalent minutes are shown in each box; Right: Temperature elevation curves for custom made drill bit are substantially lower.

Drilling longer intervals results in higher maximal peaks but also in an overall shorter time of temperature exposure. This is due to the (on average) faster moving heat source and the low thermal conductivity of bone (circa $0.55 \mathrm{~W} / \mathrm{mk}$ [37]) which limits the spread of heat. Longer time exposures for shorter interval lengths can be justified if the maximal reached temperature can be decreased significantly. The reason for this is the equation (1) which is more sensitive to temperature elevation than time duration. The thermal threshold for bone necrosis is, for example, $47^{\circ} \mathrm{C}$ for 1 minute [7] which is equivalent to CEM43 = 16min. An introduced temperature of $48{ }^{\circ} \mathrm{C}$ for 1 minute would double the CEM43 dose to $32 \mathrm{~min}$.

Different thresholds for thermal damage for different tissues can be found in literature [38. Considering the time and temperature elevation (Figure 8 of the drilling process at a single point, the thermal threshold for bone necrosis (CEM43 = 16min.) translates to a maximal allowed temperature peak of circa $50^{\circ} \mathrm{C}$ with current process parameters for a base of physiological temperature $\left(36.7^{\circ} \mathrm{C}\right)$ (compare Figure 8). Converting this to the room temperature measurements $\left(24^{\circ} \mathrm{C}\right)$, the maximum reached temperature should not exceed $37.5^{\circ} \mathrm{C}$. This threshold is slightly higher $\left(\leq 40^{\circ} \mathrm{C}\right)$ or lower $\left(\approx 35^{\circ} \mathrm{C}\right)$ for other tissues 
(e.g. nerves) or process parameters (e.g. different interval lengths result in shorter overall time exposure).

For these experiments, three different thresholds were applied on the data measured maximal temperatures. The simulation of the Bayesian random effects model allows an estimation of the probabilities to be below these thresholds for each observed parameter combination (see Figure 9). As mentioned, the threshold level for a smaller drilling interval is slightly lower. Therefore, three different thresholds were considered. ID 8 (irrigation $30 \mathrm{ml} / \mathrm{min}$, interval 0.5 $\mathrm{mm}$ ) clearly is the safest parameter combination for drilling.

Thermal threshold
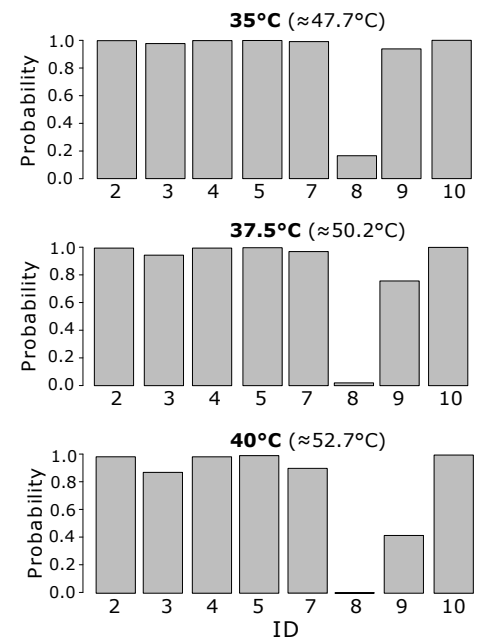

Figure 9: Probabilities of parameter combinations (ID's) to exceed a certain temperature threshold. The three thresholds were chosen to represent different thresholds for tissue damage or different time-temperature relationships. Temperature values in brackets denote the corresponding threshold value for body temperature.

\subsection{Drilling Forces and Torques}

To further analyze the measured temperature elevations and to explain the different behaviors of the drill bits, it is necessary to evaluate the drilling forces and torques. Therefore, the thrust forces and torques were compared in Figure 10 for the different input parameters without considering drilling depth. The first general observation is that high temperature peaks, due to flute clogging, coincide with highest thrust force and torque peaks. 

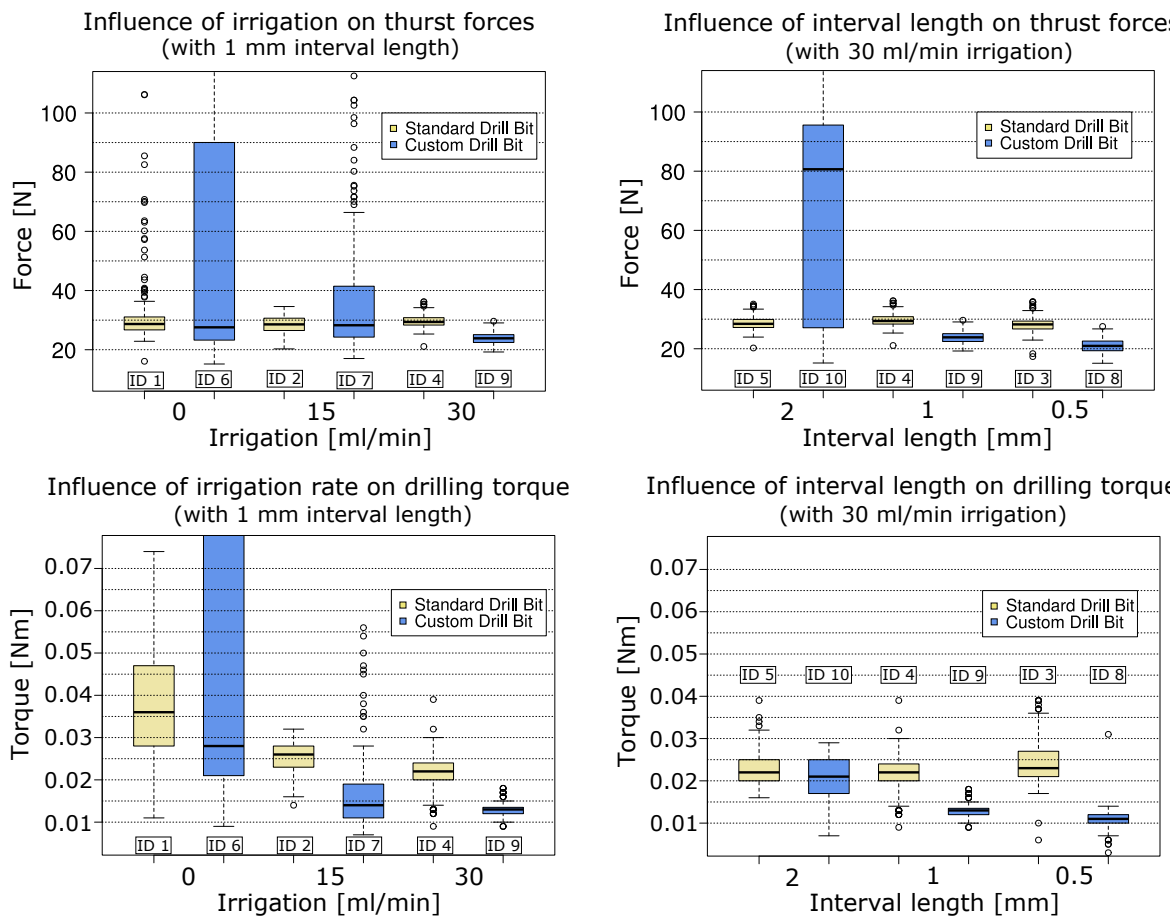

Figure 10: Thrust forces and torques for all parameter combinations. Increasing the irrigation rate reduces the issue of chip stucking for both drill bits, while drilling in intervals is only beneficial for the custom drill bit.

Figure 10 shows that increasing the amount of irrigation reduces the high thrust force and torque peaks. The effect of flute cleaning is apparently more effective for the two flutes drill bit. The new drill bit needs $30 \mathrm{ml} / \mathrm{min}$ to drill without bone chips clogging the flutes which is the reason for high peaks. This correlates to the findings for temperature elevation.

Comparing the thrust force differences for the different interval lengths reveals that there are no relevant differences for the forces and torques of the standard drill bit. However, a large reduction in thrust forces was found for the custom made drill bit between $2 \mathrm{~mm}$ and $1 \mathrm{~mm}$ interval. This hints that flute clogging is an issue for larger drilled intervals and thrust forces seem to capture this effect better. But most importantly, the forces and especially the torques of the custom drill bit can be further reduced by decreasing the interval length. This 
behavior explains the lower temperature elevation for smaller intervals of the custom drill bit in comparison with the standard drill bit.

To analyze the (linear) relationship of temperature and force, as well as the relationship of temperature and torque, again for each ID separate random effects models were used to adjust for the dependencies among the observations given by the repetition (Table 2). Restricted maximum likelihood (REML) was used to fit these models. The resulting coefficients of determination $\left(R^{2}\right)$ correspond to the proportion of variance explained by both the fixed factors (force or torque) and the random factor (repetition) [39]. Both thrust forces and torque appear to be able to describe temperature elevation.

Table 2: $R^{2}$ values for the random effects models shows correlation between force, torque and temperature elevation for each parameter combination

\begin{tabular}{r|cccccccc} 
ID & 2 & 3 & 4 & 5 & 7 & 8 & 9 & 10 \\
\hline Force & 0.7918 & 0.7546 & 0.7735 & 0.8140 & 0.6409 & 0.7710 & 0.6643 & 0.8878 \\
\hline Torque & 0.7529 & 0.8352 & 0.8306 & 0.8023 & 0.6778 & 0.7951 & 0.8005 & 0.8137
\end{tabular}

\subsection{Bone Chips}

In order to investigate the differences of the cutting behavior of the two drill bits, the produced bone chips were analyzed. Figure 11 shows a microscope (ICC50 HD, Leica, Germany) picture with the same magnification (5x) of the typical chips of the standard drill bit (left) and the new drill bit (right). It can be clearly seen that the bone chips of the standard drill bit are fractured into small pieces, while the new drill bit cuts a long continuous spiral helical chip.
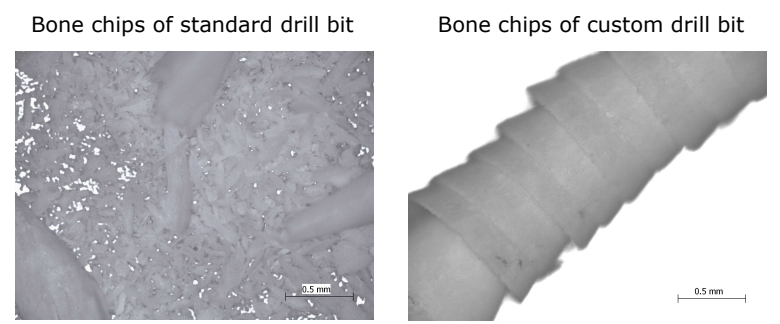

Figure 11: Left: Fractured bone chips of standard drill bit. Right: Continuous helical bone chip of custom drill bit. Continuously cut chips show improved cutting efficiency, while fractured chips are more easy to evacuate. 


\section{Discussion}

The aim of this research was to find optimized process parameters which allow the controlled drilling of deep holes in the vicinity of nerves. To test the drill bit designs and different process parameters, a new test setup has been developed. The suggested setup for measuring temperatures, thrust forces and torques of a drilling process in bone improves previous setups, but the temperature elevations are in the same magnitude as previously reported [40] [10. The advantages include the continuous measurement of the whole temperature field, drilling forces and torques at any depth with a variability of input process parameters (spindle speed, axial movement) as well as controlled irrigation. Exact placement, contact problems and only point measurements with thermocouples are avoided. The main disadvantage is the time consuming sample preparation technique and the limitation to measure temperatures starting at $5 \mathrm{~mm}$ (to prevent water leakage onto the thermographic area). This limitation is expected to have minimal impact due to the low dependency of temperature on drilling depth for these experiments. Due to the low thermal conductivity of bone, it is also possible to use small samples which have limited boundary effects on the temperature of the drilling process.

The main input process parameters (irrigation, interval length and drill bit design) were chosen for investigation because these parameters are used in the industry for temperature control during the drilling process. Results clearly suggest that irrigation is the main factor for reducing the temperature. However, irrigation is mostly associated with cooling the drill bit by convection and conduction, but the results show that a doubling of the flow rate $(15 \mathrm{ml} / \mathrm{min}$ to $30 \mathrm{ml} / \mathrm{min}$ ) seems not to be relevant for further reduction of temperature elevation. Instead, the more prominent effect is the flute clearing and therefore reducing the chance to encounter particularly high temperature peaks. This agrees with the observation that these high temperature peaks occur simultaneously with higher force and torque peaks when chips clog the flutes and are not cleared by the water jet. A constant high irrigation flow rate $(30 \mathrm{ml} / \mathrm{min})$ 
in combination with a small needle (e.g. 18 gauge) creates a water jet with sufficient pressure in the direction of the drill bit tip (angled to helix) which allows to clear the flutes when the drill bit is extracted as the irrigation fluid does not reach the machining face at a deeper drilling depth. The only effect is the cool-down of the drill bit shaft which functions as a heat sink. Also, it would be possible to use a smaller irrigation needle with a reduced flow rate or an internally irrigated drill bit as suggested by Augustin et al. [24].

Drilling in intervals has two advantages: It allows an intermittent evacuation of the bone chips as well as a discontinuous heat deposition into the bone, which limits the maximum temperature rise. Additionally, the bone is able to cool down in between the intervals which is enhanced by the irrigation. The irrigation fluid can enter the drilled hole and clear the flutes when the drill bit is extracted and lower the temperature in the bone even at deep drilling depths. This also explains the weak dependency of temperature on drilling depth. However, reducing the interval length is much more beneficial for limiting the temperature rise using the new drill bit design.

The reason for this can be found when comparing thrust forces and torques of both drill bits. The results show that the forces and torques of the custom drill bit can be significantly lowered with a decreasing interval length. This sensitivity allows a more efficient cut at smaller intervals $(0.5 \mathrm{~mm}$ and $1 \mathrm{~mm})$ compared to the standard drill bit. This is most likely due to the sharper cutting edge (higher rake angle) and/ or reduced chisel edge as well as higher cutting depth per cutting edge of the new drill bit which was hypothesized to reduce temperature elevation because it needs less force/ torque to cut bone. Drilling in small intervals might be unfeasible in a clinical setting due to the longer drilling time. A solution could be a combination of continuous or large interval drilling with smaller intervals close to the more vulnerable structures.

However, bone chips were more likely to clog the flutes at larger drilled intervals $(2 \mathrm{~mm})$ especially for the newly designed drill bit. The new drill bit design produced continuous helical bone chips which are known to be due to a higher rake angle [41] as seen in Figure 11. This chip type hints at a more efficient cut 
while it has a higher chip to volume ratio and is more difficult to evacuate than fractured chips [13].

Assessment of how thrust forces and torques relate to temperature elevation reveals a high correlation $\left(R^{2} \approx 0.8\right)$ for most parameter combination tested in this study. These values hint that forces and torques could be used for temperature prediction or detection of bone chips clogging the flutes. For the measured data, thrust force seems to be a better indicator for these flute clogging issues, while torque can possibly better capture the overall cutting efficiency.

The remaining question is which of the investigated parameter combination is safe to use. To answer this question, one has to apply the thermal threshold level to the data and calculate the equivalent cumulative equivalent minutes. In this study, different temperature thresholds were applied (Figure 9) to evaluate different thresholds of tissue damage. It was found that the only parameter combination which was significantly below the possibility to exceed any of those thresholds was the combination of new drill bit, high irrigation $(30 \mathrm{ml} / \mathrm{min})$ and small interval $(0.5 \mathrm{~mm})$. All other combinations violated all applied thresholds. All these findings are more applicable to controlled or robotic surgeries and especially useful for minimally invasive surgeries like the minimally invasive robotic cochlear implantation and other surgeries close to sensitive structures (e.g. nerves). Nonetheless, the general found relationships might help to understand and minimize the temperature elevation also in the conventional manual drilling process. However, it is still unclear to which extent necrosis of cortical and cancellous bone in orthopaedic surgeries leads to a longer healing time and for example to screw loosening and more in vivo studies are warranted. Further investigation could focus in more detail on the tool geometry (e.g. rake, point, relief angle and diameter), number and design on flutes (e.g. parabolic), drill wear and quality control in a clinical environment. 


\section{Conclusion}

This study investigated the influence of irrigation, interval and drill bit design on temperature elevation, thrust forces and torques of bone drilling at any depth using a newly designed experimental setup. External irrigation had a major effect on temperature reduction, where the effect of flute clearing is more important than actual cooling. Due to the low thermal conductivity of bone, drilling in intervals is in general beneficial for limiting the accumulation of heat and allowing the bone to cool down in-between intervals while improving chip evacuation as well as flute cleaning when the drill bit is extracted. Flute clogging with bone chips has been found to be the reason for the above-average peaks of temperatures, forces and torques which leads to excessive temperature rise.

The proposed new drill bit design with a higher rake angle $\left(35^{\circ}\right)$ and minimized chisel edge showed much lower maximum temperature elevation than the standard surgical drill bit for optimized process parameters using a high amount of irrigation $(30 \mathrm{ml} / \mathrm{min})$ and low continuously drilled interval length $(0.5 \mathrm{~mm})$. This combination was also the only one which enables a safe drilling without harming bone or surrounding tissues.

In conclusion, an improved drilling method has been found which could allow the drilling of more delicate procedures like the minimally invasive robotic cochlear implantation where nerves might be harmed by temperature elevation.

\section{Acknowledgment}

The authors would also like to thank Dr. JuEun Lee for her valuable contributions during her stay in our research group. Additionally we would like to acknowledge Nano Tera and the Swiss National Science Foundation for funding the research (16-954) within the hear restore project (RTD 2013) as well as Prof. Stefan Weber and Dr. Kate Gavaghan for their support. We declare no conflict of interest and no ethical approval was required. 


\section{References}

\section{References}

[1] G. Augustin, T. Zigman, S. Davila, T. Udilljak, T. Staroveski, D. Brezak, S. Babic, Cortical bone drilling and thermal osteonecrosis, Clinical biomechanics (Bristol, Avon) 27 (4) (2012) 313-25.

[2] R. K. Pandey, S. Panda, Drilling of bone: A comprehensive review, Journal of Clinical Orthopaedics and Trauma 4 (1) (2013) 15-30.

[3] N. Bertollo, W. Walsh, Drilling of Bone: Practicality, Limitations and Complications Associated with Surgical Drill-Bits, 2011.

[4] B. L. Tai, A. C. Palmisano, B. Belmont, T. A. Irwin, J. Holmes, A. J. Shih, Numerical evaluation of sequential bone drilling strategies based on thermal damage, Medical Engineering and Physics 37 (9) (2015) 855-861.

[5] M. Marco, M. Rodriguez-Millan, C. Santiuste, E. Giner, M. H. Miguelez, A review on recent advances in numerical modelling of bone cutting, Journal of the Mechanical Behavior of Biomedical Materials 44 (2015) 179-201.

[6] A. Feldmann, J. Anso, B. Bell, T. Williamson, K. Gavaghan, N. Gerber, H. Rohrbach, P. Zysset, Temperature Prediction Model for Bone Drilling Based on Density Distribution and In Vivo Experiments for Minimally Invasive Robotic Cochlear Implantation, Annals of Biomedical Engineering.

[7] R. Eriksson, T. Albrektsson, The Effect of heat on bone regeneration: An experimental study in the rabbit using the bone growth chamber, Journal of Oral and Maxillofacial Surgery 42 (1984) 705-711.

[8] B. Bell, C. Stieger, N. Gerber, M. Caversaccio, S. Weber, A self-developed and constructer robot for minimally invasive cochlear implantation, Acta oto-laryngologica 132 (2012) 355-360. 
[9] R. F. Labadie, R. Balachandran, J. H. Noble, G. S. Blachon, J. E. Mitchell, F. a. Reda, B. M. Dawant, J. M. Fitzpatrick, Minimally invasive imageguided cochlear implantation surgery: First report of clinical implementation, The Laryngoscope (2013) 1-8.

[10] J. Lee, O. B. Ozdoganlar, Y. Rabin, An experimental investigation on thermal exposure during bone drilling, Medical engineering \& physics 34 (10) (2012) 1510-20.

[11] C. H. Jacobs, J. T. Berry, A study of the bone machining process - drilling, Journal of Biomechanics 9 (1976) 343-349.

[12] S. Saha, S. Pal, J. A. Albright, Surgical drilling: Design and Performance of an Improved Drill, Journal of Biomechanical Engineering 104 (1982) $245-252$.

[13] V. P. Astakhov, Drills: Science and Technology of Advanced Operations, CRC Press, 2014.

[14] N. Bertollo, H. R. M. Milne, L. P. Ellis, P. C. Stephens, R. M. Gillies, W. R. Walsh, A comparison of the thermal properties of 2- and 3-fluted drills and the effects on bone cell viability and screw pull-out strength in an ovine model., Clinical biomechanics (Bristol, Avon) 25 (6) (2010) 613-7.

[15] N. Bertollo, T. K. Gothelf, W. R. Walsh, 3-Fluted orthopaedic drills exhibit superior bending stiffness to their 2-fluted rivals: clinical implications for targeting ability and the incidence of drill-bit failure., Injury 39 (7) (2008) $734-41$.

[16] V. Kalidindi, Optimization of drill design and coolant sytem during dental implant surgery, Ph.D. thesis (2004).

[17] G. Augustin, S. Davila, K. Mihoci, T. Udiljak, D. S. Vedrina, A. Antabak, Thermal osteonecrosis and bone drilling parameters revisited., Archives of orthopaedic and trauma surgery 128 (1) (2008) 71-7. 
[18] N. Sugita, M. Mitsuishi, Specifications for machining the bovine cortical bone in relation to its microstructure, Journal of biomechanics 42 (16) (2009) 2826-9.

[19] J. Soriano, A. Garay, P. Aristimuño, P. J. Arrazola, Study and improvement of surgical drill bit geometry for implant site preparation, The International Journal of Advanced Manufacturing Technology 74 (5) (2014) 615-627.

[20] N. Sugita, K. Ishii, J. Sui, M. Terashima, Multi-grooved cutting tool to reduce cutting force and temperature during bone machining, CIRP Annals - Manufacturing Technology 63 (1) (2014) 101-104.

[21] C. Natali, P. Ingle, J. Dowell, Orthopaedic bone drills-can they be improved? Temperature changes near the drilling face., The Journal of bone and joint surgery. British volume 78 (3) (1996) 357-62.

[22] K. L. Wiggins, S. Malkin, Drilling of bone, Journal of Biomechanics 9 (1976) 553-559.

[23] B. L. Tai, A. C. Wang, A. J. Shih, S. E. Sullivan, Cool Mist Irrigation Improves Heat Dissipation during Surgical Bone Drilling, Journal of Neurological Surgery 75 (2014) 243-246.

[24] G. Augustin, S. Davila, T. Udilljak, T. Staroveški, D. Brezak, S. Babić, Temperature changes during cortical bone drilling with a newly designed step drill and an interally cooled drill, International Orthopadics 36 (7) (2012) 1449-1456.

[25] K. Wiggins, S. Malkin, Orthogonal machining of bone, Journal of Biomechanical Engineering 100 (1978) 122-130.

[26] J. Sui, N. Sugita, K. Ishii, K. Harada, M. Mitsuishi, Force Analysis of Orthogonal Cutting of Bovine Cortical Bone, Machining Science and Technology 17 (4) (2013) 637-649. 
[27] T. H. C. Childs, D. Arola, Machining of Cortical Bone: Simulations of Chip Formation Mechanics Using Metal Machining Models, Machining Science and Technology 15 (2) (2011) 206-230.

[28] G. D. Strbac, E. Unger, R. Donner, M. Bijak, G. Watzek, W. Zechner, Thermal effects of a combined irrigation method during implant site drilling. A standardized in vitro study using a bovine rib model., Clinical oral implants research (2012) 1-10.

[29] S. A. Gehrke, H. L. Neto, F. E. C. Mardegan, Investigation of the effect of movement and irrigation systems on temperature in the conventional drilling of cortical bone., The British journal of oral \& maxillofacial surgery (2013) 6-10.

[30] L. S. Matthews, C. Hirsch, Temperatues measured in human cortial bone when drilling, The Journal of bone and joint surgery 54-A (1) (1972) 297308.

[31] B. C. Sener, G. Dergin, B. Gursoy, E. Kelesoglu, I. Slih, Effects of irrigation temperature on heat control in vitro at different drilling depths., Clinical oral implants research 20 (3) (2009) 294-8.

[32] S. C. Isler, E. Cansiz, C. Tanyel, M. Soluk, F. Selvi, Z. Cebi, The effect of irrigation temperature on bone healing., International journal of medical sciences 8 (8) (2011) 704-8.

[33] A. Feldmann, P. Zysset, Experimental determination of the emissivity of bone, Medical Engineering and Physics (2016) 8-12.

[34] J. D. Currey, Bones: Structure and Mechanics, Princeton University Press, Princeton, 2006.

[35] K. Risse, Einflüsse von Werkzeugdurchmesser und Schneidkantenverrundung beim Bohren mit Wendelbohrern in Stahl, Phd thesis, RWTH Aachen (2006). 
[36] S. A. Sapareto, W. C. Dewey, Thermal dose determination in cancer therapy, International Journal of Radiation Oncology, Biology, Physics 10 (1984) 787-800.

[37] S. R. Davidson, D. F. James, Measurement of thermal conductivity of bovine cortical bone, Medical engineering \& physics 22 (10) (2000) 741-7.

[38] P. Yarmolenko, E. Moon, Thresholds for thermal damage to normal tissues: An update, International Journal of Hyperthermia 27 (4) (2011) 320-343.

[39] S. Nakagawa, H. Schielzeth, A general and simple method for obtaining R 2 from generalized linear mixed-effects models, Methods in Ecology and Evolution 4 (2013) 133-142.

[40] G. Augustin, S. Davila, T. Udiljak, D. S. Vedrina, D. Bagatin, Determination of spatial distribution of increase in bone temperature during drilling by infrared thermography: preliminary report., Archives of orthopaedic and trauma surgery 129 (5) (2009) 703-9.

[41] S. F. F. Malak, I. A. Anderson, Orthogonal cutting of cancellous bone with application to the harvesting of bone autograft, Medical engineering \& physics 30 (2008) 717-724. 